\title{
TERREMOTO en Talca/Chile
}

\section{Kena Lorenzini ${ }^{1}$}

\begin{abstract}
Para bien de los ricos necesariamente tienen que existir los pobres... una perogrullada en estable descuido.
\end{abstract}

Las consecuencias del terremoto y maremoto están hiperbolizando a ambos grupos. Lo estamos presagiando cada día a través de las políticas adoptadas por el nuevo gobierno de derecha (no de centro derecha, ya atesoramos suficientes eufemismos) quien esta cediendo la reconstrucción a las grandes empresas privadas nacionales y transnacionales, de las siguientes maneras (entre otras): la compra de insumos de construcción a las tres grandes cadenas ferreteras (demanda por colusión de precios ya ingresada), la concesión (por una cantidad enigmática de años) de la construcción de los hospitales públicos devastados. Así también el Estado comprará a privados las casas que se entregaran (expuestas ya en salones feriales) a los damnificados que cumplan con el requisito de no haber recibido nunca subsidio habitacional y que tengan en sus manos el correspondiente "Certificado de inhabitabilidad" de su vivienda. Anexemos la sospechosa solidaridad de los principales actores del mercado encadenada al consumo "tu nos compras uno, nosotros nos ponemos con uno". La lista es vasta.

Talca, a dos días del terremoto. La ciudad esta poblada de escombros y de categórica solidaridad entre quienes están damnificados. En Santiagola TV seengolosina reiterando una y otra vez las imágenes de saqueos y llantos. La televisión caló poderosamente haciendo dudar a las personas de las vivencias propias, y saturando de terror a quienes estaban lejos o fuera del país. Una TV farandulera que aprovechó de vender publicidad y sus rostros, una TV que no cumplió con su responsabilidad de informar, ciertamente ocurrían hechos más trascendentales que los (¿escasos?) saqueos.

Un ejemplo ilustrativo del comportamiento de la TV en su también pugna por el rating, es que en el momento en que 
socorristas intentaban rescatar personas del edificio más colapsado de la catástrofe, un conocido conductor se introdujo por una de las perforaciones realizadas especialmente para el salvataje y requirió a uno de los rescatistas que le enseñara el instrumental que estaban utilizando y, con celo especial desea saber cómo funciona esa camarita espía que se puede introducir en todos los rincones, una copia infeliz de la TV de ese momento. (He expuesto en extenso este patrón de relato, fue ineludible no hacerlo).

Talca, a dos días del terremoto. Abundancia de improvisadas carpas. En esta catástrofe terráquea hubo muchos damnificados que hacen parte de la clase media quienes perdieron sus viviendas porque Talca es (era) una ciudad de adobe. Felizmente esta clase media poseía (en general) alimentos para soportar los primeros días, donde era posible se consumían aquellos que peligraban por falta de refrigeración. Pero todxs, sin excepción probaron la carencia de agua, luz y comunicaciones. Los más preventivos o hobbistas tenían radio a pilas y/o linternas. Nos cuentan la experiencia de una familia con cinco niños que ha perdido su vivienda pero que padre y madre deciden acampar en el jardín e intentar que los hijos se sacudan de los temores tomándose una semana de plazo para buscar una solución. Un privilegio para una familia con red de apoyo.

Talca, a dos días del terremoto. En la placilla de la 8 oriente un cura hace misa al aire libre, a las afueras de la parte nueva del hospital Talca (vilipendiado hasta el hartazgo) que se podía apreciar sin daños almuerzan protegidos por toldos parte del personal. Sabemos la historia de una madre de 79 años que hace dedo a las 5 AM para ir a ver a su hija que vive en el campo en una casa de adobe y de una joven que recorre en bicicleta las casas de los mayores recogiendo celulares porque alguien ha ofrecido cargarlos con un generador que un otro proporcionaba unas horas al día.

Talca, dos meses después del terremoto. Nos dicen los talquinxs que no les es posible olvidar que hubo un terremoto, que el polvo por los inmuebles que se están demoliendo llena los pulmones, que las carpas se llueven, que las mediaguas que han llegado son insuficientes, y que algunos favorecidos (tal vez del 


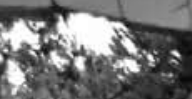

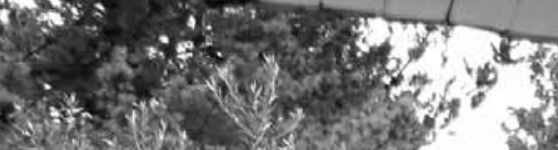
ath

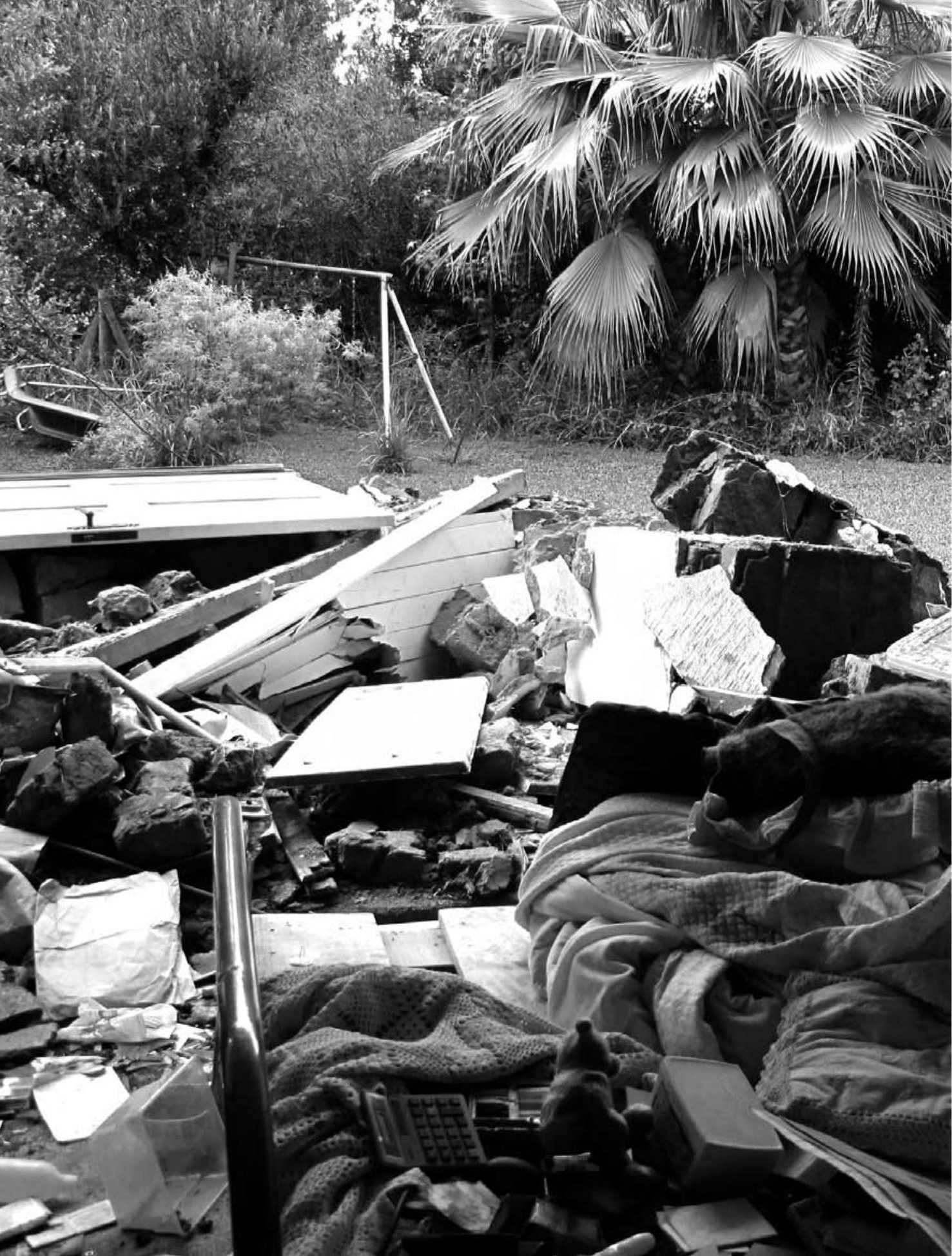




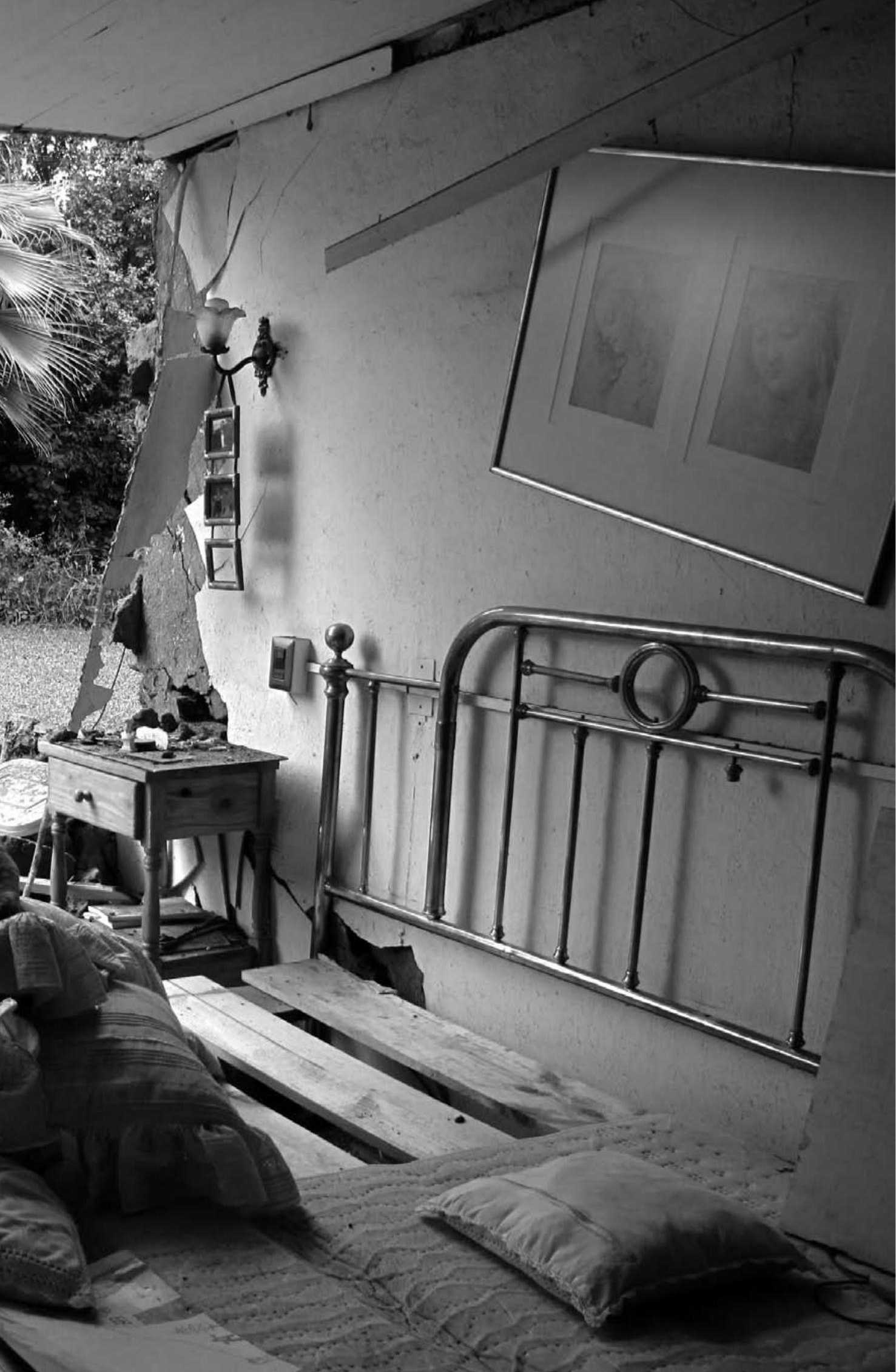




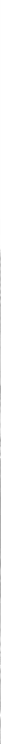

complejo habitacional de Las Rastras) que superaron o no probaron nunca el sabor de la emergencia pasan veloces en sus automóviles por el lado de las carpas levantando más polvadera y ruido. Ellos sí han olvidando. Olvidado que en el interior de esos entoldados hay personas en circunstancias desgraciadas. Nos cuentan que las organizaciones de la sociedad civil se han constituidos, que auxilian y enlistan las necesidades, y que el alcalde (que pertenece al conglomerado de gobierno) los ha apoyado en su demanda contra la angustiante lentitud del poder ejecutivo.

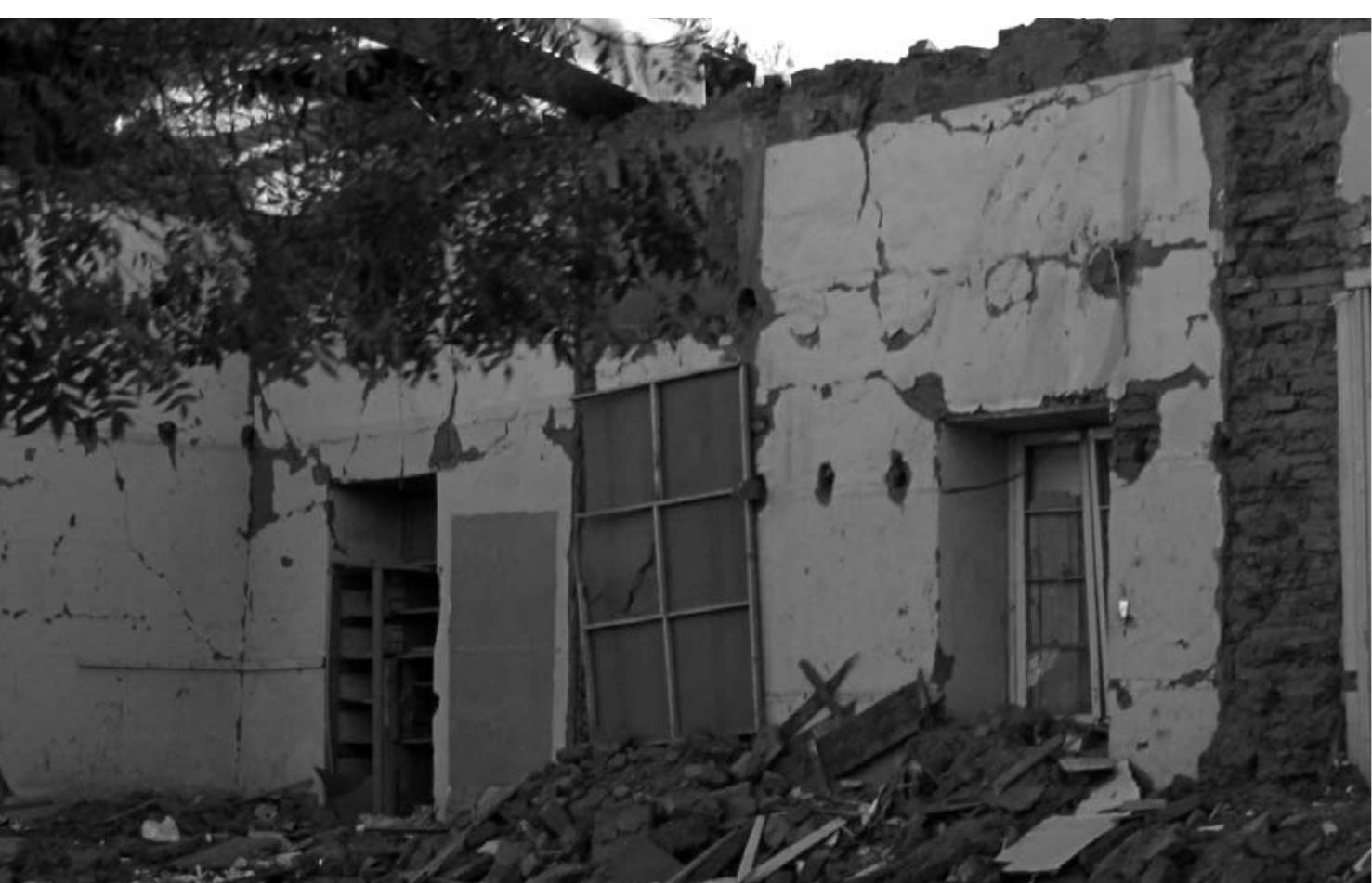




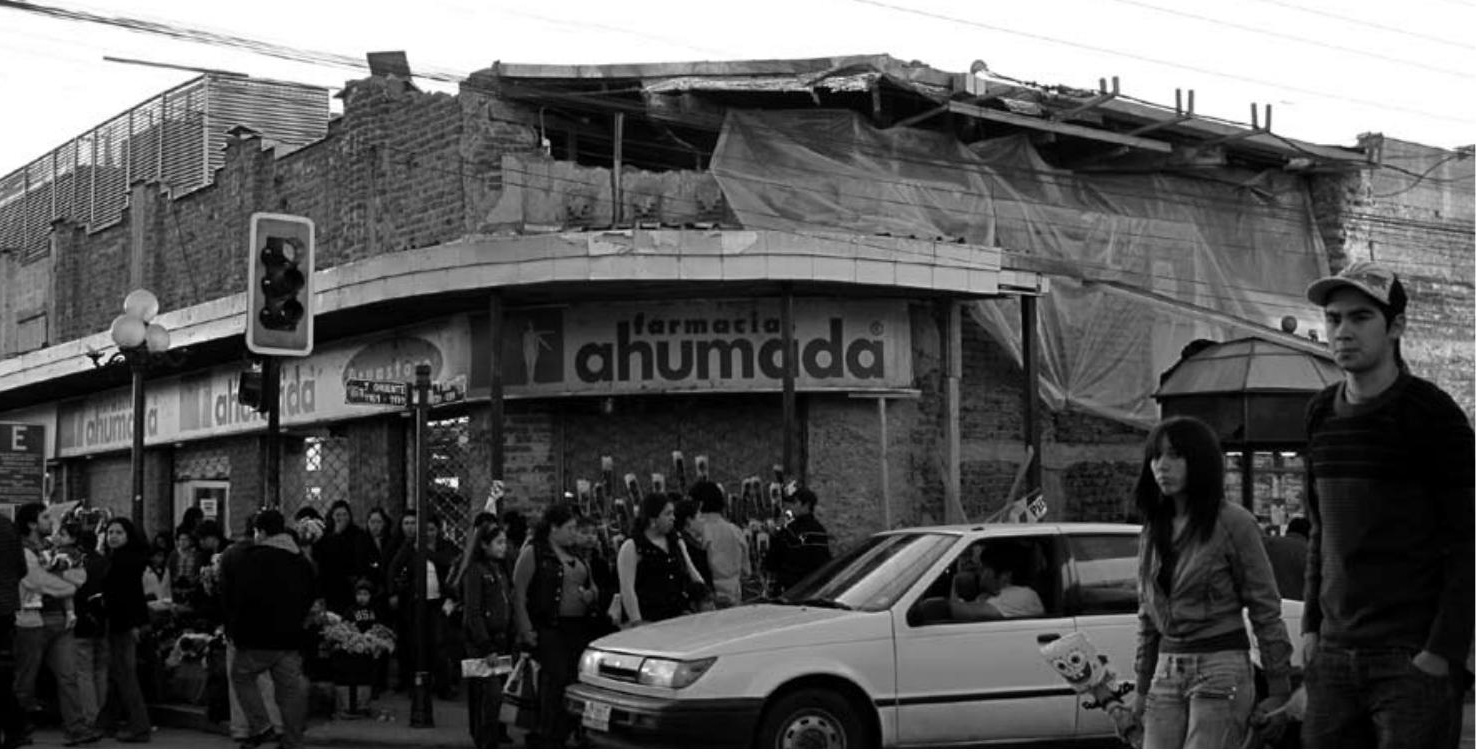

En Santiago en cambio, hasta el Presidente (al mes y medio de la catástrofe) pone fin a la emergencia, con eso y sólo un poco más, para la mayoría se cierra un capítulo y sus vidas son reanudadas. Con indiferencia.

Talca, dos meses después del terremoto. Nos cuentan de una mujer que solicita dinero para reconstruir una capilla que mantienen los campesinos en una zona rural. (Dios nos protegerá, dicen. ¿Por qué no los protegió antes?).Vemos que las iglesias de la ciudad

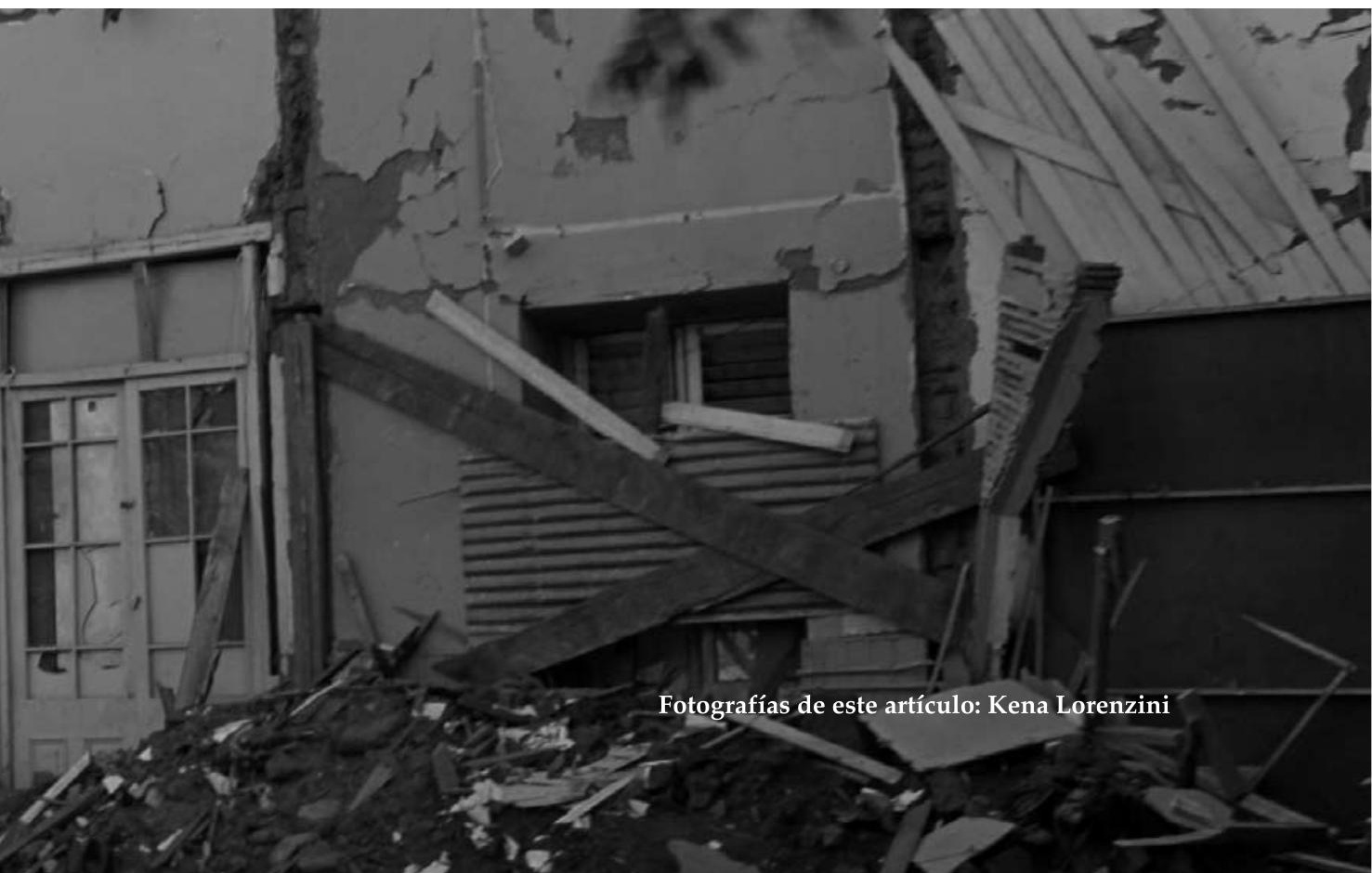


en su mayoría perdieron sus cúpulas que anhelaban llegar al cielo, y que sus dueños pregonan no tener recursos para reconstruirlas.

Talca, dos meses después del terremoto. Hay esquinas totalmente despojadas, ya sin restos, vértices desolados que hacían parte de la calle eje de la ciudad. Los edificios del correo y la gobernación deberán ser demolidos. El intendente nominado por el nuevo gobierno es dueño de una importante inmobiliaria de la ciudad que terminó con varias de sus construcciones dañadas por lo que las personas le reclaman doblemente, como intendente y como empresario. Hay desasosiego respecto de la reconstrucción.

Talca, a dos meses del terremoto. El comercio se ha desplomado hacia las calles, las compra/ventas se hacen en las veredas y la gente consume en exceso para mitigar la ansiedad dicen, nada nos parece raro.

Suceden tantas cosas en Talca, en Constitución, en Dichato, en Concepción, en Talcahuano, en San Javier, en Yerbas Buenas... en Santiago, post terremoto y maremoto, que demasiados se están empobreciendo.

19 mayo 2010

Nota

1 Fotógrafa y psicóloga. 